\title{
ANÁLISE DA REALIZAÇÃO DO MORFEMA -ED POR ESTUDANTES BRASILEIROS DE INGLÊS EM UMA PERSPECTIVA COMPLEXA DA LINGUAGEM
}

\author{
Analysis of the morpheme -ed realization by Brazilian students \\ of English in a complex perspective of language
}

\author{
Antônio Alexandre de ARAÚJO \\ Universidade do Estado do Rio Grande do Norte \\ alex.emcristo@hotmail.com \\ https://orcid.org/0000-0001-5475-1190 \\ Clerton Luiz Felix BARBOZA \\ Universidade do Estado do Rio Grande do Norte \\ clertonluiz@gmail.com \\ https://orcid.org/0000-0002-3498-4795
}

\begin{abstract}
RESUMO: O objetivo deste estudo é analisar a realização do morfema -ed dos verbos regulares por aprendizes brasileiros de inglês língua adicional. Temos por pergunta-problema: como as variáveis palavra e indivíduo influenciam a realização alvo do morfema -ed dos verbos regulares do inglês? Como hipótese básica, assumimos que os aprendizes brasileiros realizam o morfema -ed de maneira complexa, apresentando diferenças significativas entre palavras e indivíduos, comportando-se de modo não-linear. Esta pesquisa baseia-se na visão de língua(gem) enquanto Sistema Adaptativo Complexo (SAC) (BECKNER et al., 2009) e nos modelos fonológicos multirrepresentacionais (BYBEE, 2001). Este estudo caracteriza-se como quase-experimental e quantitativo, cujos dados passaram por análise acústico-estatística. Os principais resultados são: (1) algumas palavras são mais propensas à realização alvo do que outras. Por serem o locus da representação mental na Fonologia de Uso, palavras podem ter o mesmo tipo fonotático, mas apresentarem comportamentos distintos; (2) alguns indivíduos apresentaram baixo índice de realização alvo, enquanto outros indivíduos apresentaram domínio da realização alvo do morfema -ed do inglês, evidenciando a existência de percursos individuais de construção da gramática fonológica mesmo entre indivíduos com nível de proficiência semelhante. PALAVRAS-CHAVE: Sistema Adaptativo Complexo; Modelos Multirrepresentacionais; Realização do morfema -ed.
\end{abstract}

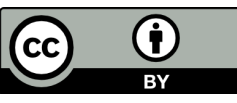




\begin{abstract}
This study aims to analyze the production of the morpheme -ed in regular verbs by Brazilian learners of English as an additional language. Our research question is: how do the variables word and individual influence the target realization of the morpheme -ed of English regular verbs? The hypothesis states Brazilian learners produce the morpheme -ed in a complex way, presenting significant differences between words and individuals, behaving non-linearly. This research is based on a view of language as a Complex Adaptive System (CAS) (BECKNER et al., 2009) and the multi-representational phonologic models (BYBEE, 2001). This is a quasi-experimental and quantitative research, with data undergoing acoustic-statistical analyses. The main results are: (1) some words are less favorable to the production of the morpheme -ed than others. Once the words are the locus of mental representation in Usage-Based Phonology, although they have the same phonotactic type, they may present distinct behavior; (2) some individuals showed lower rates of target production, while other individuals showed higher rates of target realization of the morpheme -ed, making clear the existence of individual pathways of construction of the phonological grammar even between individuals with similar proficiency level. KEYWORDS: Complex Adaptive System; Multi-representational models; Realization of the morpheme -ed.
\end{abstract}

\title{
INTRODUÇÃO
}

O objetivo desta pesquisa é analisar a realização do morfema -ed dos verbos regulares por aprendizes brasileiros de inglês língua adicional (doravante ILA). A pergunta-problema que norteia este estudo é: de que maneira as variáveis palavra e indivíduo estão associadas à realização alvo do morfema -ed dos verbos regulares do inglês? Como hipótese básica, assumimos que os aprendizes brasileiros realizam o morfema -ed de maneira complexa, apresentando diferenças significativas entre palavras e indivíduos, comportando-se de modo não-linear. Esta pesquisa baseia-se na visão de língua(gem) enquanto Sistema Adaptativo Complexo (SAC) (LARSENFREEMAN, 2008; BECKNER et al., 2009) e nos preceitos dos Modelos Fonológicos Multirrepresentacionais (PIERREHUMBERT, 2001; BYBEE, 2001). Ressaltamos que poucas pesquisas resenhadas neste trabalho abordaram seus resultados sob uma perspectiva dinâmica, o que nos motivou a buscar preencher tal lacuna na literatura quanto à abordagem do morfema -ed.

Ao longo dos anos e em pesquisas mais recentes, focou-se na instrução explícita na aquisição do morfema -ed (ALVES, 2004) e na relação entre treinamento e a instrução explícita (MARIANO, 2009), na percepção (FRESE, 2006), na inteligibilidade (RIELLA, 
2013; DELATORRE, 2017), bem como na produção do morfema -ed (DELATORRE, 2006; GOMES, 2009; GADÊLHA-SILVA, 2019). O presente estudo busca aprofundar a discussão ao analisar realizações do morfema -ed numa perspectiva complexa, levando em consideração as variáveis palavra e indivíduo, através de uma pesquisa quantitativa quase-experimental, com foco no detalhe fonético de realização.

Após esta breve seção de Introdução, é apresentada a Fundamentação Teórica do trabalho, que foca em pesquisas que investigaram o morfema -ed por aprendizes brasileiros. A seção Metodologia apresenta as informações metodológicas da pesquisa, seguida pelos Resultados e Discussão. Por fim, são apresentadas as Considerações Finais do estudo.

\section{FUNDAMENTAÇÃO TEÓRICA}

Adotamos neste trabalho a visão de língua(gem) enquanto SAC (LARSENFREEMAN; CAMERON, 2008; BECKNER et al., 2009), dos Modelos Multirrepresentacionais, como a Fonologia de Uso (BYBEE, 2001), e da noção probabilística do Modelo de Exemplares (PIERREHUMBERT, 2001). Apresentamos a seguir uma breve discussão envolvendo a realização do morfema -ed dos verbos regulares do inglês sob a ótica desses pressupostos.

Concebemos neste trabalho uma visão distinta da linguística gerativista tradicional, que preconiza a língua(gem) como um sistema inato capaz de ativar um conjunto de regras preestabelecidas na mente do falante. Em vez disso, advogamos que a língua(gem) é um ambiente em que diversos componentes interagem de maneira complexa e dinâmica, sendo regulada por um grande número de variáveis, emergindo a partir do uso linguístico (BAICCHI, 2015).

A língua(gem) conta com atratores, que tendem a influenciar alguma característica do sistema. Apesar de tais sistemas serem, inerentemente, instáveis, eles apresentam comportamentos emergentes que podem se tornar estáveis por certo período de tempo. Larsen-Freeman e Cameron (2008, p. 49) definem atratores como "estados, ou modos de comportamentos particulares, que o sistema "prefere". Quando o sistema se move para uma bacia atratora, ele atinge um momento de estabilidade (CRISTÓFARO-SILVA; GOMES, 2004). Na realização do morfema -ed, por exemplo, o vozeamento atua como um atrator, uma vez que segmentos vozeados anteriores ao morfema favorecem a emergência do alomorfe d, enquanto segmentos desvozeados favorecem a emergência do alomorfe t. O conceito de atratores é fundamental para o estudo dos padrões silábicos, pois diversos fatores mostram-se em competição, apresentando maior ou menor influência 
para a realização do morfema -ed e consequente alteração do comportamento do sistema. Fatores como o tempo de exposição à língua adicional, idade, contexto de aprendizagem, entre muitos outros podem ser brevemente mencionados. Adicionalmente, a língua(gem) também se caracteriza como um sistema aberto, pois conta com a influência de sistemas externos, realizando, permanentemente, trocas de informações, baseadas, por exemplo, na competição entre formas-alvo do inglês, apresentadas de modo explícito e sistemático, com a tendência do aprendiz de deixar-se levar pela influência grafofônica ou pela fonologia do português brasileiro ao realizar o morfema -ed. Sobre essa característica dos SACs, Johnson e Britain (2007, p. 16) afirma que "muito mais comuns são os sistemas que, de alguma forma, estão em contato com o mundo externo". Segundo Larsen Freeman e Cameron (2008), um sistema aberto se renova constantemente a partir de um fluxo contínuo de energia que é naturalmente introduzido no sistema.

Por sua vez, os Modelos Multirrepresentacionais assumem que as representações linguísticas são múltiplas e detalhadas (BYBEE, 2001; PIERREHUMBERT, 2001). Inexiste neste caso a separação entre fatos fonéticos e fatos fonológicos, peculiar às teorias fonológicas tradicionais. Para tais modelos, as representações fonológicas correspondem diretamente àquelas encontradas na realização fonética, apresentando uma representação mental complexa e um mapeamento simples (CRISTÓFAROSILVA; GOMES, 2004). Para esta visão, a palavra é o locus da representação mental. O armazenamento linguístico é realizado através de nuvens de exemplares. Itens lexicais, adquiridos pelo uso da língua, são armazenados em redes de acordo com aspectos sonoros, semânticos e/ou morfológicos. O detalhe fonético é importante na construção das representações fonológicas. A realização dos exemplares é baseada em escolhas probabilísticas, com itens de maior frequência apresentando maior robustez (BYBEE, 2001; PIERREHUMBERT, 2001). Assim, tais teorias consideram que o sistema fonéticofonológico é múltiplo e detalhado, que há uma inter-relação entre os diversos sistemas linguísticos, com a variação presente no percurso individual de construção linguística dos falantes sendo representada também na abstração fonológica.

Passamos à abordagem do fenômeno analisado, além de discutirmos estudos sobre o tema na interfonologia Português Brasileiro/Inglês Língua Adicional (PB/ILA). Na Figura 1, ilustramos uma nuvem de exemplares em competição, buscando representar graficamente a representação mental da palavra kissed, e as múltiplas realizações possíveis do morfema -ed por aprendizes brasileiros. Os exemplares estão apresentados em diferentes cores e tamanhos a fim de evidenciar a variação durante sua realização, 
que pode advir de fatores como idade, tempo de exposição à língua alvo, indivíduo, experiência de uso, falar regional, etc.

Figura 1: Nuvem de exemplares em competição da palavra kissed.

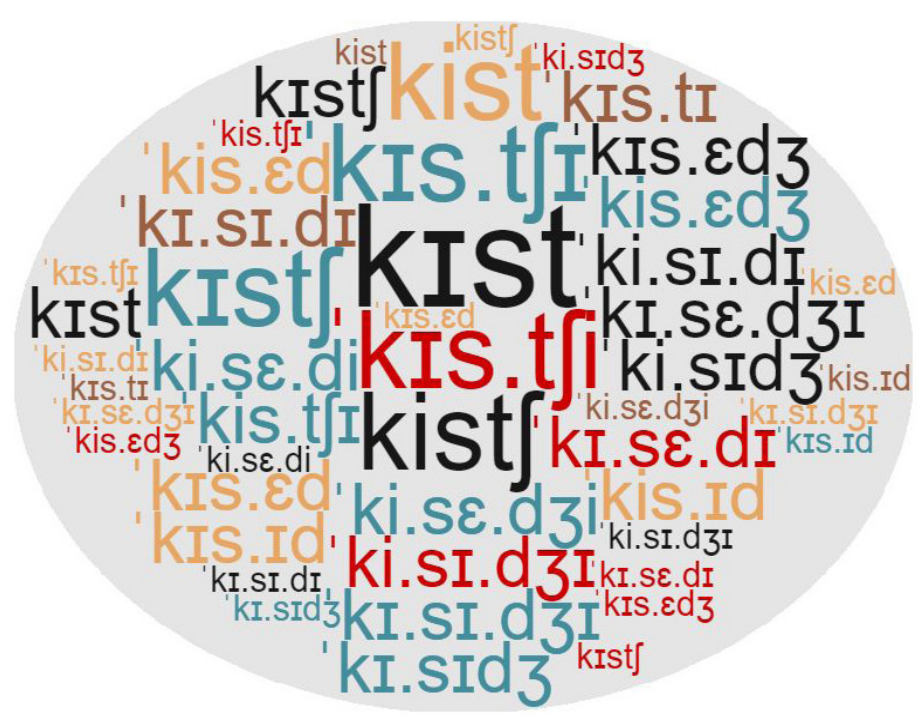

Fonte: Elaboração dos autores.

$\mathrm{Na}$ Figura 1, observamos diferentes exemplares em competição da palavra kissed, armazenados no repertório linguístico do aprendiz brasileiro de ILA. A forma alvo de realização do morfema -ed corresponde ao alomorfe $\mathbf{t}$, pois a forma subjacente do morfema -ed, que conforme a literatura é d (ALVES, 2004; GOMES, 2009), deve ser realizada como $\mathbf{t}$ quando o contexto fonológico anterior é composto de consoante desvozeada. No entanto, durante o percurso inicial de aquisição da gramática fonológica do ILA, os aprendizes brasileiros tendem a inserir uma vogal epentética anterior alta ' kIs.Id ou média ' kıs.ed durante a realização do -ed no passado dos verbos, por provável influência do grafema <e>. Há realizações em que emerge uma epêntese final 'kı.sı.dı, 'kı.se.dı ou ' kıs.tı. É comum também os aprendizes realizarem na primeira sílaba a vogal alta anterior 'kis.ıd ou 'kis.ed em vez de realizarem a vogal média-alta anterior 'kıs.ıd. Além disso, falantes da maioria das regiões do Brasil costumam palatalizar a consoante final do verbo 'kı.sıdz e kıst], bem como inserir a vogal epentética após a palatalização 
'kI.SI.dzI e 'kIs.tfI. Toda essa variação faz parte da construção da gramática fonológica, até alcançarem a realização fonética da forma alvo kist (ao centro superior, na cor escura). Estudos que abordam a realização do morfema -ed são discutidos a seguir.

Alves (2004) analisou o efeito da instrução explícita na realização do morfema -ed por aprendizes brasileiros de nível universitário. $\mathrm{O}$ autor investigou a realização de encontros consonantais em verbos regulares em um pré-teste e em dois pós-testes. $\mathrm{O}$ resultado da pesquisa evidenciou que a realização esperada ocorreu da seguinte forma: no período pré-instrucional foi 24\% (fala espontânea) e 16,6\% (leitura), enquanto no período pós-instrucional 1 foi 50,9\% (fala espontânea) e 56,8\% (leitura), e no período pós-instrucional 2 foi 51,2\% (fala espontânea) e 61,1\% (leitura). Os dados mostram que a intervenção pedagógica realizada com os alunos que participaram da pesquisa contribuiu para melhorar sua produção dos detalhes associados à realização do morfema -ed.

Trabalho semelhante foi realizado por Mariano (2009). A pesquisadora fez um estudo comparativo da relação entre treinamento e instrução explícita, e sua influência na realização do morfema -ed. A autora investigou a realização do passado de verbos regulares em pré- e pós-testes. Os informantes foram divididos em três grupos: Grupo Treinamento, Grupo Instrução e Grupo Controle. No período pós-teste, observou-se que no Grupo Instrução o percentual de realização esperada foi de 50\%, enquanto no Grupo Treinamento foi 37\%, e no Grupo Controle 32\%. Os dados são semelhantes aos reportados por Alves (2004), corroborando a importância da instrução explícita na realização de palavras com o morfema -ed.

No que diz respeito à percepção e sua relação com a produção dos alomorfes do morfema -ed, mencionamos o trabalho de Frese (2006). Na pesquisa foram realizados dois testes, um de produção e outro de percepção. Os informantes demonstraram melhor resultado na produção quando o morfema -ed estava associado ao alomorfe Id (93,7\%), e apresentaram desempenho inferior quando tiveram que associar o morfema -ed aos alomorfes $\mathbf{t}(42,6 \%)$ e d $(21,1 \%)$. Em relação à percepção, os resultados mostraram que os participantes discriminaram mais acuradamente o alomorfe Id $(79,6 \%)$, seguido do alomorfe $\mathbf{t}(73,4 \%)$ e do alomorfe $\mathbf{d}(61,1 \%)$.

Riella (2013) buscou investigar se a ocorrência de epêntese influenciava na inteligibilidade da fala do aprendiz brasileiro de ILA. Os informantes foram divididos em três grupos distintos: G1 (falantes nativos de inglês), G2 (aprendizes brasileiros de ILA) e G3 (falantes do inglês com diferentes L1s). Os resultados da pesquisa mostraram que apesar da ocorrência de epêntese na realização do -ed, e suas possíveis influências na comunicação, a inteligibilidade das palavras terminadas em -ed foi relativamente alta. 
Tanto G1 quanto G2 tiveram o mesmo índice geral de compreensão das frases escutadas (71\%). Apenas G3 mostrou um índice menor de inteligibilidade (60\%).

Delatorre (2017) também focou na inteligibilidade de verbos terminados em -ed. A pesquisadora buscou investigar a correlação da familiaridade com alguns verbos regulares, a proficiência e a experiência no inglês dos aprendizes com a inteligibilidade. A autora buscou também averiguar a influência da L1 (PB, espanhol, alemão ou inglês) na inteligibilidade dos verbos terminados em -ed para os aprendizes brasileiros de inglês. Outra questão analisada pela autora foi como o tipo de alomorfe do morfema -ed (t, d, Id) afeta a inteligibilidade dos verbos regulares do inglês por aprendizes brasileiros. Os resultados do estudo de Delatorre (2017) confirmaram a hipótese de que a inteligibilidade está correlacionada à familiaridade dos informantes com os verbos testados, bem como sua proficiência e experiência no inglês. O resultado da pesquisa também mostrou que aprendizes brasileiros compreendem e transcrevem ortograficamente de modo mais acurado verbos produzidos por falantes não nativos do inglês, em relação aos falantes nativos. $\mathrm{O}$ estudo demonstrou que os diferentes alomorfes do morfema -ed não influenciaram a inteligibilidade dos verbos. Foram constatados valores aproximados de inteligibilidade dos ouvintes em relação aos verbos terminados nos alomorfes t e Id $(48,2 \%)$ e nos verbos terminados no alomorfe $\mathbf{d}(46,4 \%)$.

No tocante à produção de palavras terminadas no morfema -ed, Delatorre (2006) analisou a ocorrência da vogal epentética medial no passado dos verbos regulares de ILA. A autora buscou investigar de que maneira fatores como a marcação, o contexto fonológico e a ortografia influenciam na ocorrência de epêntese durante a realização de palavras com o morfema -ed. Os resultados mostraram que a realização do morfema -ed com encontros consonantais de três elementos (CCC), como em fixed fikst, induzem maior realização de epêntese medial $(89,5 \%)$ do que encontros consonantais compostos de dois elementos (CC), como na palavra liked larkt (79,6\%). Delatorre (2006) também concluiu que, no que tange à influência do contexto fonológico precedente, os aprendizes foram mais induzidos à inserção da epêntese em contextos consonantais $(82,5 \%)$ do que em contextos vocálicos $(50 \%)$. O teste qui-quadrado demonstrou que a produção de epêntese em contextos consonantais, como em stopped e called, por exemplo, foi significativamente maior do que em contextos vocálicos, como em played e cried.

Gomes (2009) focou sua pesquisa na realização do morfema -ed por aprendizes brasileiros de ILA e buscou investigar as influências do contexto fonológico e grafofônico na realização do morfema -ed. Além de considerar estas variáveis, a pesquisadora considerou o nível de proficiência na língua, o tempo de instrução formal e o tempo de 
exposição à língua em país de língua inglesa, como variáveis relevantes para análise em seu trabalho. Como resultado, os aprendizes realizaram as palavras terminadas em -ed com a presença de epêntese entre o segmento final da base do verbo e a consoante oclusiva alveolar em 54\% dos casos. A autora constatou ainda que a realização de epêntese pelos informantes nas palavras com os alomorfes $\mathbf{t}$ e $\mathbf{d}$ aumenta significativamente sob influência de segmento fricativo ou oclusivo precedente ao morfema -ed.

Finalmente, Gadêlha-Silva (2019) analisou a realização de verbos terminados em -ed por aprendizes brasileiros de ILA, numa perspectiva multirrepresentacional da língua(gem). A autora fundamentou seu trabalho na Teoria Acústica da Produção da Fala (KENT; READ, 2015; MARUSSO, 2005), na Fonologia de Uso (BYBEE, 2002) e no Modelo de Exemplares (PIERREHUMBERT, 2001). O estudo da variável indivíduo foi levado em conta devido ao arcabouço teórico utilizado pela autora. As teorias adotadas consideram a variação interindividual relevante no percurso de aquisição da gramática fonológica do inglês pelo aprendiz brasileiro de ILA. Os resultados desta variável indicaram variação significativa entre os participantes da pesquisa. Havendo no nível préintermediário, masculino, destaque para o informante com o menor percentual de epêntese $(0 \%)$. Enquanto houve informante que apresentou grande percentual de realização epentética no experimento $(78,5 \%)$. Em relação à variável vozeamento, Gadêlha-Silva (2019) destacou que houve maior emergência de epêntese vocálica na realização do morfema -ed em contextos desvozeados (82,3\%). Tal resultado confirma os achados de Delatorre (2006), indicando a preferência da epêntese pelos contextos desvozeados.

Os trabalhos supracitados buscaram investigar ao longo dos anos, sob diferentes perspectivas teóricas, os fatores que levam um aprendiz brasileiro de ILA a realizar o morfema -ed dos verbos no passado regular com a emergência de epêntese vocálica. Esses trabalhos trouxeram importantes contribuições ao estudo da interfonologia do morfema -ed dos verbos regulares do inglês, seja na busca dos efeitos da instrução, na área da inteligibilidade, e no campo da produção ou percepção.

Encerramos neste momento a seção de referencial teórico da pesquisa. A próxima seção apresenta os procedimentos metodológicos do estudo.

\section{METODOLOGIA}

Este estudo caracteriza-se como uma pesquisa quase-experimental, quantitativa, de cunho transversal. Foram selecionados 20 informantes de nível universitário, sendo 10 de semestres iniciais ( $1^{\circ}$ e $2^{\circ}$ semestres), e 10 de semestres finais ( $7^{\circ}$ e $8^{\circ}$ semestres) do curso de Letras - Inglês da Universidade do Estado do Rio Grande do Norte - UERN. 
A coleta de dados ocorreu entre os semestres 2020.1 e 2020.2. Devido à necessidade de isolamento social decorrente da COVID-19, a coleta dos dados foi realizada on-line, mediante a utilização do gravador de voz para celular Easy Voice ${ }^{1}$.

Em trabalhos mais recentes, Larsen-Freeman $(2015,2021)$ menciona que apenas conseguimos mensurar e falar sobre desenvolvimento linguístico quando se geram dados longitudinais e que consideram o indivíduo, não apenas o grupo. Neste sentido, neste trabalho, de cunho transversal, está se usando a teoria do SAC apenas como uma lente teórica para análise dos dados.

Voluntariaram-se informantes de ambos os sexos, com idade de 17 a 35 anos (média: 23; desvio padrão: 5,8), naturais de diversas cidades do Rio Grande do Norte. A variável dependente desta pesquisa é a Realização do Morfema - $\boldsymbol{e d}$, classificado enquanto forma alvo ou não. As variáveis independentes desta pesquisa são: (a) Palavra - tendo em vista que para este trabalho nos baseamos na Fonologia de Uso (BYBEE, 2001) e no Modelo de Exemplares (PIERREHUMBERT, 2001), advogamos que cada item lexical está sujeito a um percurso de desenvolvimento distinto, estando mais ou menos propenso à realização alvo do morfema -ed; e, (b) Indivíduo - observamos o comportamento individual dos informantes. Acredita-se que cada indivíduo apresenta características distintas quanto à realização do morfema -ed.

Os informantes realizaram três vezes cada palavra (verbos no passado regular). O estudo realizou dois experimentos. Foram analisados 2.040 dados, sendo 1.440 no Experimento 1, e 600 no Experimento 2. O Experimento 1 consistiu na leitura de diferentes frases-veículo, cada uma delas contendo um verbo no passado regular. Foram utilizadas frases como The thief robbed a bank, She worked for a big company, The bus stopped near school, entre outras. O Experimento 2 caracterizou-se pela leitura de algumas sentenças utilizadas no primeiro experimento, com utilização de imagens. Buscou-se analisar as realizações das palavras selecionadas evitando a influência grafofônica através da descrição de imagens que expressassem as ações verbais. Os informantes foram orientados a realizarem as frases no passado simples. No total, foram selecionadas 24 palavras contendo o morfema -ed, apresentadas no Quadro 1, para compor os experimentos deste estudo. Foram utilizados os contextos oclusivos b, g, p, $\mathbf{k}$ e fricativos $\mathbf{v}, \mathbf{z}, \mathbf{f}$, s precedentes ao morfema -ed (alomorfes $\mathbf{d}$ e t), na seleção das palavras terminadas em -ed utilizadas nos experimentos.

1 Disponível em: https://easy-voice-recorder.br.uptodown.com. Acesso em 20 de Julho de 2021. Revista X, v. 16, n. 6, p. 1434-1459, 2021. 
Quadro 1: Palavras selecionadas.

\begin{tabular}{|l|c|}
\hline \multicolumn{2}{|c|}{ Contextos oclusivos e as palavras utilizadas nos experimentos } \\
\hline \multirow{2}{*}{ Contextos vozeados } & $\mathbf{b d}$ - grabbed, robbed, disturbed \\
\cline { 2 - 2 } & $\mathbf{g d}$ - begged, hugged, prolonged \\
\hline \multirow{2}{*}{ Contextos desvozeados } & $\mathbf{p t}$ - stopped, helped, developed \\
\cline { 2 - 2 } Contextos fricativo-oclusivos e as palavras utilizadas nos experimentos \\
\hline \multirow{2}{*}{ Contextos vozeados } & $\mathbf{k d}$ - talked, loved, saved, involved \\
\cline { 2 - 2 } & $\mathbf{z d}$ - used, closed, supposed \\
\hline \multirow{2}{*}{ Contextos desvozeados } & $\mathbf{f t}$ - laughed, coughed, sniffed \\
\cline { 2 - 2 } & $\mathbf{s t ~ - ~ m i s s e d , ~ p a s s e d , ~ i m p r e s s e d ~}$ \\
\hline
\end{tabular}

Fonte: Elaboração dos autores.

Para a análise estatística, foi utilizado o software IBM SPSS Statistics, versão 23 (IBM CORPORATION, 2015). O teste estatístico utilizado foi o qui-quadrado de aderência, para as análises categóricas de realização da variável dependente de realização do morfema - ed, juntamente com o teste de tamanho de efeito V de Cramer, de acordo com recomendações da literatura (DANCEY; REIDY, 2006). Após a realização do quiquadrado de aderência, foi realizada uma análise dos resíduos ajustados para a escala $\mathrm{Z}$ em cada célula (SHARP, 2015), propiciando uma análise post-hoc do qui-quadrado por meio da correção de Bonferroni. A Figura 2 apresenta o oscilograma e espectrograma da palavra stopped, em sua realização esperada sta:pt. 
Figura 2: Oscilograma e espectrograma da palavra stopped em sua forma esperada.
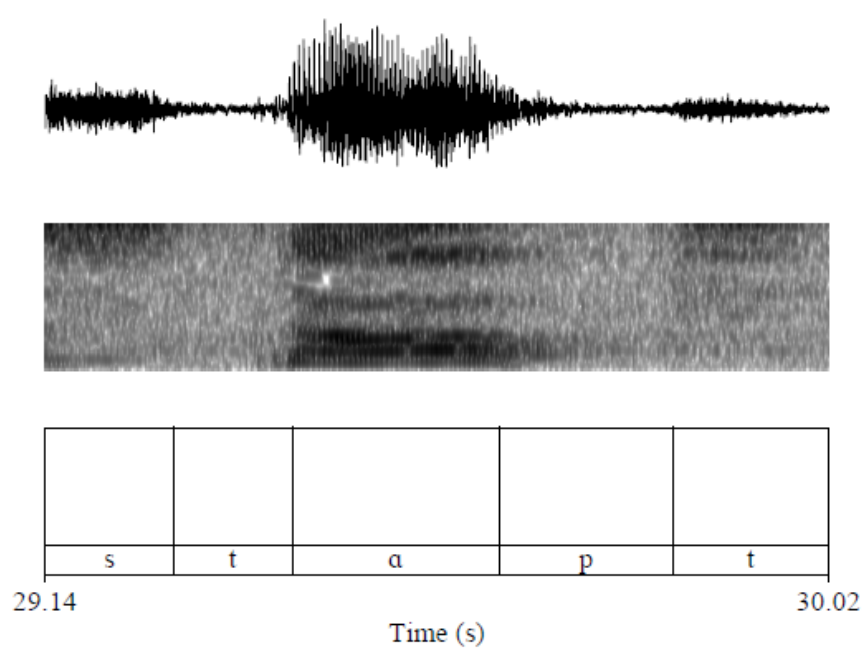

Fonte: Acervo pessoal, extraído das gravações dos áudios no programa Praat.

A Figura 2 ilustra a realização esperada da palavra stopped, em que o morfema -ed corresponde ao alomorfe t, uma vez que o contexto fonológico anterior ao morfema é o segmento desvozeado $\mathbf{p}$, o que propicia a realização desvozeada do morfema -ed. A Figura 3 representa o oscilograma e espectrograma da palavra stopped, em sua forma não esperada, com a ocorrência da vogal epentética medial $\boldsymbol{\varepsilon}$ ('sta:.ped).

Figura 3: Oscilograma e espectrograma da palavra stopped em sua forma não esperada.
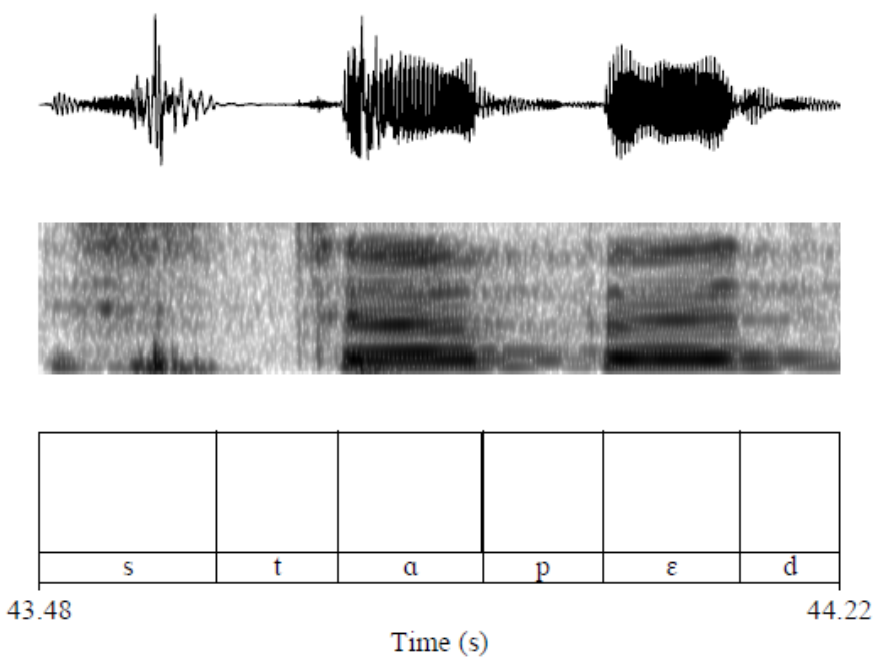

Fonte: Acervo pessoal, extraído das gravações dos áudios no programa Praat. 
Na Figura 3 ilustramos o verbo stopped sendo realizado com a realização da vogal epentética $\boldsymbol{\varepsilon}$ entre o segmento final da base do verbo $\mathbf{p}$ e a consoante oclusiva alveolar $\mathbf{d}$. A realização do morfema -ed com a ocorrência de epêntese vocálica é recorrente durante o percurso de aquisição da gramática fonológica do inglês por aprendizes brasileiros, que utilizam a modificação da estrutura silábica de palavras com o morfema -ed como estratégia para facilitar sua realização. $\mathrm{Na}$ próxima seção apresentamos a análise e discussão dos dados desta pesquisa.

\section{RESULTADOS E DISCUSSÃO}

Iniciamos a discussão analisando a variável palavra, a fim de averiguar itens lexicais distintos que favoreçam ou desfavoreçam a realização alvo do morfema -ed dos verbos regulares do inglês. Os dados obtidos no Experimento 1, de leitura de frasesveículo, são expostos na Figura 4.

Figura 4: Realização alvo das palavras com o morfema -ed no Experimento 1.

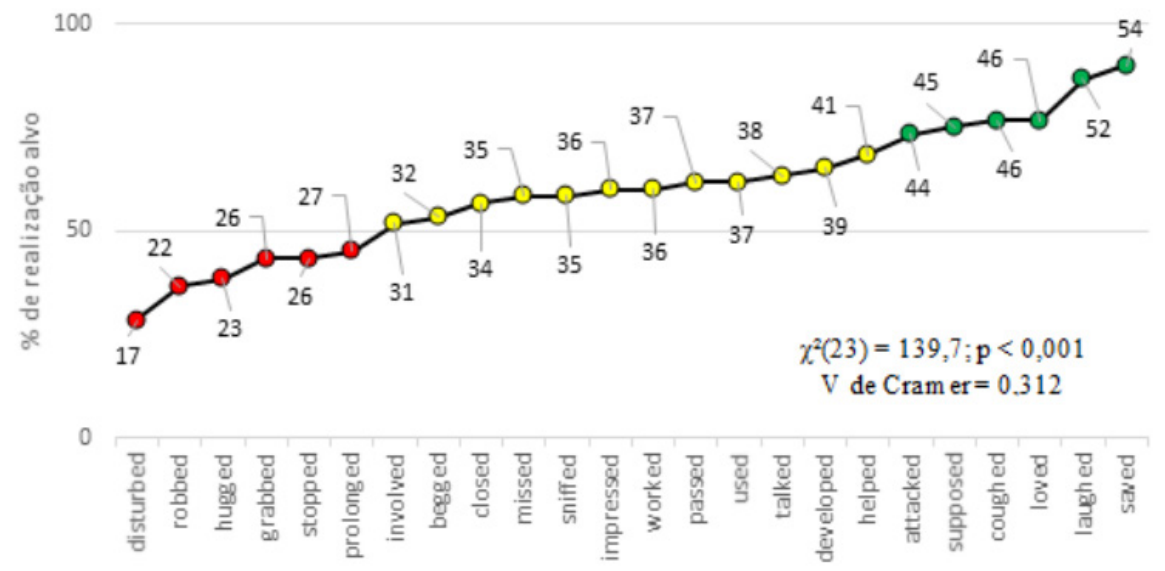

Fonte: Elaboração dos autores.

Devido à grande quantidade de informações apresentadas na Figura 4, realizamos um comentário pormenorizado de sua elaboração a seguir. O eixo y (vertical) apresenta os dados da variável dependente realização do morfema -ed. Buscando uma melhor visualização, apenas os dados de realização alvo são apresentados. Os valores no extremo esquerdo do gráfico 0, 50 e 100 são percentuais. O eixo x (horizontal) apresenta cada uma das 24 palavras analisadas neste estudo. As palavras foram organizadas em ordem crescente da realização alvo do morfema -ed. Cada palavra está associada a um marcador, 
que pode ter três cores. $\mathrm{O}$ vermelho indica palavras que apresentam resistência, o amarelo indica comportamento neutro, e o verde indica favorecimento da realização alvo do morfema -ed, segundo a análise estatística. Desse modo, a palavra disturbed, cujo marcador é vermelho indicando uma palavra resistente à forma alvo, tem apenas 17 realizações apropriadas do morfema -ed. A palavra used, cujo marcado é amarelo indicando neutralidade quanto à forma alvo, tem 37 realizações alvo. Finalmente, a palavra saved, cujo marcador é verde indicando favorecimento da forma alvo, tem 54 realizações alvo do morfema -ed. Passamos à análise dos dados da Figura 4 a seguir.

A análise estatística inferencial dos dados apresentados na Figura 4 indicou um valor alto para o qui-quadrado $\left(\chi^{2}(23)=139,7\right)$. Sendo muito baixa a probabilidade de os resultados serem decorrentes do erro amostral $(\mathrm{p}<0,001)$. Adicionalmente, o V de Cramer obtido foi de 0,312 , indicando que cerca de $9,7 \%$ da variação na realização do morfema -ed pode ser explicada pela variável palavra. Conclui-se que a realização de palavras diferentes influencia de modo significativo a emergência alvo do morfema -ed dos verbos regulares do inglês, conforme pressupostos dos modelos fonológicos multirrepresentacionais (BYBEE, 2001). Os resultados dos testes post-hoc com a correção de Bonferroni são discutidos a seguir.

A palavra disturbed, representada pelo primeiro marcador vermelho, mostrou-se mais resistente, contando com apenas 17 realizações alvo. Destaca-se que esta palavra conta com o padrão vozeado e termina com o contexto fonotático bd, cujas características dificultam a emergência da forma alvo e favorecem a vogal epentética (DELATORRE, 2006; GOMES, 2009). Outras palavras que apresentaram resistência à forma alvo foram robbed, hugged, grabbed, stopped e prolonged, apresentadas também com marcadores vermelhos. Constata-se que palavras terminadas pelos contextos vozeados bd e gd apresentaram os menores índices de realização da forma alvo. Observa-se que todas as três palavras terminadas em bd favoreceram a vogal epentética. Todavia, destaca-se no grupo a palavra stopped como único item lexical que, embora terminado em contexto desvozeado pt, apresentou inesperadamente baixo índice de realização alvo. Pode-se hipotetizar que o fator preponderante neste caso seja o ponto de articulação, semelhante ao homorgânico bd que apresentou baixa emergência da forma alvo, e não o vozeamento. Todavia essa hipótese pode ser falsa, uma vez que outras palavras em pt apresentaram comportamento neutro como veremos a seguir. Tal resultado manifesta a não-linearidade do sistema linguístico, conforme preconizado pela visão de língua enquanto Sistema Adaptativo Complexo (LARSEN-FREEMAN, 1997; BECKNER et al., 2009). 
Por sua vez, o grupo de palavras que apresentou comportamento neutro quanto à emergência da forma alvo do morfema -ed foi composto pelos itens lexicais involved, begged, closed, missed, sniffed, impressed, worked, passed, used, talked, developed e helped, indicadas pelos marcadores amarelos. Neste grupo, observa-se uma alternância entre contextos fonotáticos vozeados vd, zd, gd e desvozeados st, ft, kt, pt. Comprovase assim que a influência do vozeamento é limitada na emergência das formas alvo do morfema -ed nos dados observados, sendo a palavra uma variável mais relevante.

Finalmente, o grupo de palavras que favorece a emergência da forma alvo é composto pelos itens attacked, supposed, coughed, loved, laughed e saved, indicados pelos marcadores verdes. Novamente observamos neste grupo uma alternância entre contextos fonotáticos vozeados zd, vd e desvozeados kt, ft. O fato reforça a irrelevância do vozeamento dos contextos fonotáticos na realização alvo do morfema -ed, uma vez que palavras contendo esses tipos fonotáticos também podem ser observadas no grupo neutro (amarelo) quanto ao favorecimento ou desfavorecimento da forma alvo, sendo a palavra uma variável mais importante.

Conclui-se que os dados referentes ao Experimento 1 deste estudo indicam que, apesar de variáveis como vozeamento e contexto fonológico influenciarem a realização da forma alvo do morfema - ed, a palavra é sem dúvida uma variável que merece ser observada. Modelos fonológicos tradicionais tendem a relegar a análise da palavra a um papel secundário. Todavia, os modelos fonológicos multirrepresentacionais consideram a palavra como locus da representação mental (CRISTÓFARO-SILVA; GOMES, 2004). Os dados indicam que a realização do morfema -ed comporta-se de modo distinto mesmo quando apresentam contexto fonológico ou vozeamento idêntico, indicando comportamento semelhante à difusão lexical observada na mudança linguística em língua materna (BYBEE, 2001). Os dados ora apresentados vão ao encontro do referido paradigma, também ao observarmos dados referentes ao Experimento 2 desta pesquisa, apresentados na Figura 5. 
Figura 5: Realização alvo das palavras com o morfema -ed no experimento 2.

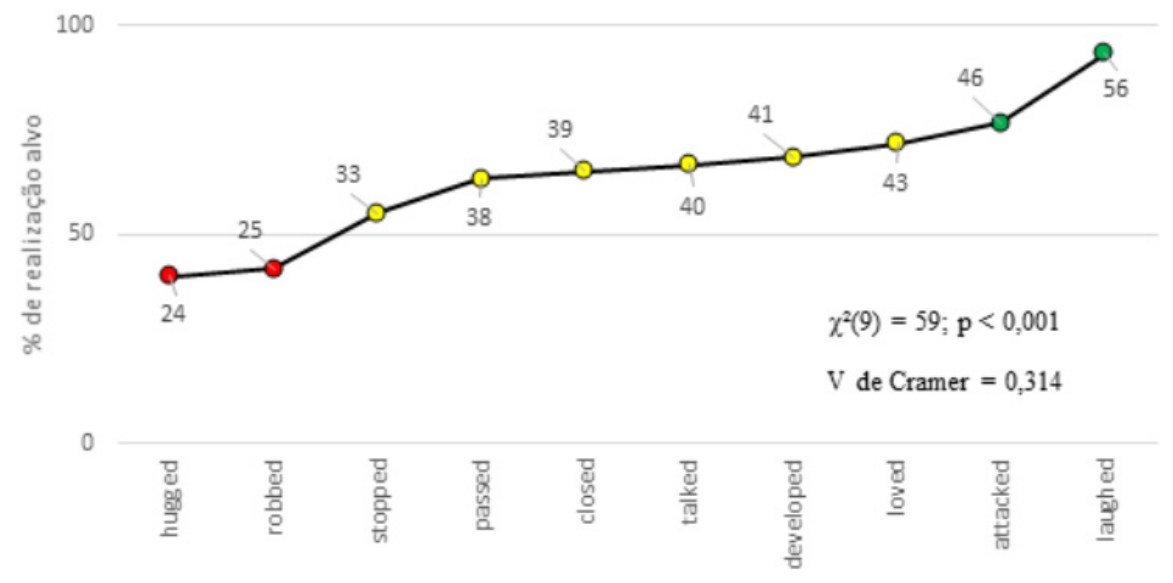

Fonte: Elaboração dos autores.

A análise estatística inferencial dos dados apresentados na Figura 5 indicou um valor alto para o qui-quadrado $\left(\chi^{2}(9)=59\right)$. Sendo muito baixa a probabilidade de os resultados serem decorrentes do erro amostral $(\mathrm{p}<0,001)$. Adicionalmente, o V de Cramer obtido foi de 0,314 , indicando que cerca de $9,9 \%$ da variação na realização do morfema -ed pode ser explicada pela variável palavra. Conclui-se que a realização de palavras diferentes influencia de modo significativo a emergência do morfema -ed dos verbos regulares do ILA também no Experimento 2, conforme pressupostos dos modelos fonológicos multirrepresentacionais (BYBEE, 2001). Os resultados dos testes post-hoc com a correção de Bonferroni são discutidos a seguir.

As palavras hugged e robbed são apresentadas em marcadores vermelhos à esquerda da figura, indicando que foram itens lexicais que se mostraram resistentes à realização alvo do morfema -ed. Lembramos que essas palavras também apresentaram resistência à forma alvo no caso do Experimento 1. De modo semelhante ao observado no Experimento 1, os dados do Experimento 2 indicam que contextos fonológicos vozeados como gd e bd são desafiadores e apresentam baixo índice de realização da forma alvo. Ressaltamos que, das quatro palavras que apresentam contexto vozeado, duas apresentaram comportamento neutro como veremos a seguir.

Por sua vez, as palavras stopped, passed, closed, talked, developed e loved apresentam comportamento neutro quanto à forma do morfema -ed, quer favorecendo ou desfavorecendo a forma alvo. Quando comparamos os dados dos Experimentos 1 e 2, observamos um comportamento complexo dos itens lexicais. Lembramos que 
no Experimento 1 usamos frases-veículos, e no Experimento 2 buscamos evitar a influência dos grafemas nas realizações, substituindo a grafia das palavras analisadas por figuras. Chamamos a atenção para o caso da palavra stopped, que era resistente no Experimento 1 e passou a ser neutra quanto à realização do morfema -ed no Experimento 2. Adicionalmente, a palavra loved, que era favorecedora no Experimento 1 passou a ser neutra no Experimento 2.

A mudança no comportamento dos referidos itens lexicais é de difícil explicação cartesiana, uma vez que stopped melhorou e loved regrediu quanto à realização da forma alvo do morfema -ed. Por outro lado, todas as outras palavras do Experimento 2 consideradas neutras também o foram no Experimento 1. A hipótese da influência grafofônica não se sustenta, tendo em vista que a literatura não aponta um padrão definido, ora com informantes apresentando tendência pela realização alvo na leitura de frasesveículo (ALVES, 2004), ora a tendência pela maior realização da forma alvo ocorrendo em experimentos de fala mais espontânea buscando evitar a influência grafofônica (DELATORRE, 2006). Fato é que este é mais um atrator estranho (LARSEN-FREEMAN; CAMERON, 2008) observado nos dados quando focamos na análise da variável palavra, mas ignorado em modelos fonológicos tradicionais que desconsideram a palavra como locus de representação mental (CRISTÓFARO-SILVA; GOMES, 2004).

Finalmente, as palavras attacked e laughed apresentaram comportamento favorável à forma alvo do morfema -ed no Experimento 2. Ambas as palavras foram também favoráveis no Experimento 1, indicando comportamento semelhante em ambos os experimentos, independente de elas terem sido lidas ou elicitadas a partir de imagens.

Desse modo, constatamos diferentes grupos de palavras com níveis de realização da forma alvo distintos, que podem ser desaforáveis, neutros ou favoráveis à realização alvo do morfema -ed dos verbos regulares do ILA. Tendo em vista os preceitos da Fonologia de Uso (BYBEE, 2001) e do Modelo de Exemplares (PIERREHUMBERT, 2001), era esperado que a emergência da forma alvo do morfema -ed apresentasse variação na realização de palavras distintas. Identificamos que a realização do morfema -ed opera de forma diferenciada a depender do item lexical, tendo em vista que encontramos palavras com contexto fonológico e vozeamento idênticos, porém com índices de realização alvo distintos. Esse achado nos leva à conclusão de que a realização alvo do morfema -ed está condicionada lexicalmente.

De maneira geral, notou-se que as palavras analisadas, independentemente de serem realizadas através de leituras de frases-veículo ou sem influência grafofônica, favoreceram ou foram neutras quanto à realização alvo do morfema -ed no ILA. Alguns 
itens lexicais como loved e saved se mostraram favoráveis à realização da forma alvo, apesar de seu contexto vozeado. Entretanto, as palavras terminadas em contextos desvozeados, bem como em contextos fonotáticos fricativo-oclusivo, foram as que proporcionaram maiores índices de realização alvo. Finalizamos neste ponto a análise da variável palavra e, a seguir, iniciamos a discussão da variável indivíduo.

A análise da variável indivíduo buscou investigar as características distintas dos informantes com relação à realização do morfema -ed do inglês. Os informantes iniciantes são identificados por meio da letra "I", seguida da numeração de 1 a 10 (I1, I2, I3, etc.). Os informantes avançados são identificados pela letra "A", seguida da numeração de 11 a 20 (A11, A12, A13, etc.). Os dados obtidos no Experimento 1 são expostos na Figura 6.

Figura 6: Realização alvo do morfema -ed por indivíduo no Experimento 1.

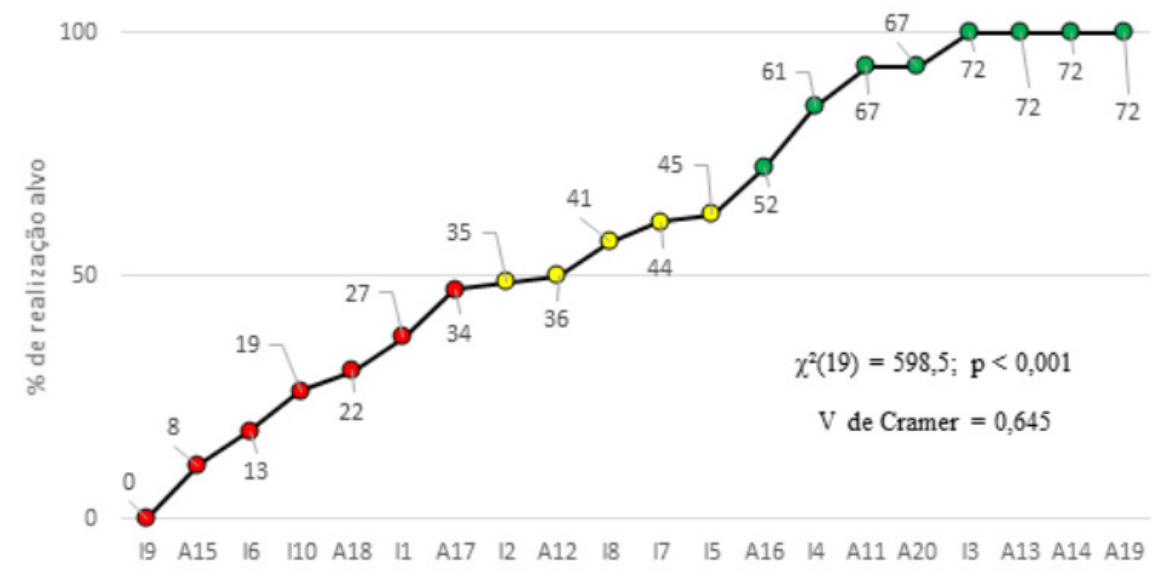

Fonte: Elaboração dos autores.

A análise estatística inferencial dos dados apresentados na Figura 6 indicou um valor alto para o qui-quadrado $\left(\chi^{2}(19)=598,5\right)$. Sendo muito baixa a probabilidade de os resultados serem decorrentes do erro amostral $(\mathrm{p}<0,001)$. Adicionalmente, o V de Cramer obtido foi de 0,645 , indicando que cerca de $41,6 \%$ da variação na realização do morfema -ed pode ser explicada pela variável indivíduo, um percentual bastante alto. Conclui-se que a variável indivíduo influencia de modo significativo a realização alvo do morfema -ed dos verbos regulares do ILA, algo esperado numa visão de língua enquanto Sistema Adaptativo Complexo (LARSEN-FREEMAN; CAMERON, 2008), uma vez que mesmo pequenas diferenças nas condições iniciais podem gerar grande variação. Todavia, a análise individual é frequentemente deixada de lado em paradigmas 
fonológicos tradicionais. A variação entre-participantes deste estudo pode ser observada na Figura 6 e nos testes de post-hoc com a correção de Bonferroni, discutidos a seguir.

Os dados relativos aos informantes que apresentam resistência à realização alvo do morfema -ed do ILA são apresentados em marcadores vermelhos, à esquerda no gráfico. O grupo é constituído de sete informantes, sendo quatro informantes iniciantes e três avançados. Chama a atenção a presença de três aprendizes avançados neste grupo (A15, A18 e A17), uma vez que todos são alunos regularmente matriculados em curso de Letras com Habilitação em Língua Inglesa, e no momento da coleta de dados estavam cursando os semestres finais. Os referidos informantes demonstraram dificuldade na realização da forma alvo do morfema, sendo essa dificuldade autoatribuída à falta de segurança na pronúncia de algumas palavras do inglês, apesar de já terem instrução explícita sobre a questão.

Adicionalmente, os informantes avançados cursaram a disciplina de Fonética e Fonologia da Língua Inglesa anteriormente, momento no qual as regularidades na realização alvo do morfema -ed dos verbos regulares do ILA é bastante enfatizada. Outro dado que chama a atenção no grupo de informantes resistentes à forma alvo é o fato de o informante 19 ser incapaz de produzir uma realização da forma esperada do morfema. Análise do questionário de anamnese do informante 19 indica uma autoavaliação bastante negativa da própria pronúncia. Se por um lado pode-se compreender essa falta de controle devido ao fato de o referido informante ser iniciante, tendo realizado a coleta de dados antes de estudo explícito da produção do morfema -ed, por outro lado temos diversos informante iniciantes nos grupos cujo comportamento é neutro ou mesmo favorecedor da forma alvo, como veremos posteriormente.

Por sua vez, o grupo com marcadores amarelos indica os informantes que apresentam comportamento neutro quanto à realização do morfema -ed, quer favorecendo ou desfavorecendo a forma alvo. Observa-se que o grupo em questão é relativamente pequeno, com apenas cinco informantes, quando comparado aos outros dois grupos. Deduz-se que o comportamento individual de aquisição da gramática fonológica do morfema, apesar de marcadamente não-linear, como esperado dos sistemas complexos (BECKNER et al., 2009), apresenta uma tendência por atratores nos extremos de produção, com poucos informantes mantendo uma variação livre entre dois profundos atratores associados à forma alvo, à direita no gráfico, e inesperada, à esquerda.

Todavia, a pedra que causa a avalanche, o fato causador da mudança pela preferência de uma realização inesperada e uma realização alvo, não parece estar associada ao estudo explícito das regularidades de pronúncia do morfema -ed, tendo em 
vista que novamente no grupo neutro observamos informantes dos grupos iniciante e avançado. A literatura indica que a instrução explícita é importante para a realização do morfema (ALVES, 2004; GOMES, 2009; MARIANO, 2009), mas os dados desta pesquisa apontam que os efeitos da instrução podem perder-se com o tempo, caso não haja reforço constante. Apesar de fugir do escopo desta pesquisa, seria pertinente o acompanhamento longitudinal dos informantes iniciantes na construção das categorias de realização do morfema -ed com o passar do tempo para a avaliação desta hipótese.

Finalmente, o grupo de marcadores verdes, à direita no gráfico, apresenta dados dos informantes cujo favorecimento da forma alvo do morfema -ed é estatisticamente significativo. Mais uma vez observamos uma composição mista, com informantes de nível iniciante e avançado no grupo. A literatura aponta que a realização alvo do morfema -ed é desafiadora para aprendizes brasileiros (DELATORRE, 2006; GOMES, 2009). Todavia, observamos neste estudo que os informantes I4 e I3, com apenas um ano de estudo na universidade e, portanto, ainda sem instrução explícita na área de fonética e fonologia, favorecem a forma alvo. O informante I3 chega mesmo a apresentar realização alvo categórica ( $100 \%$ de acerto) no Experimento 1, juntamente com outros informantes de nível avançado. Ao analisar as informações obtidas na anamnese, o informante I3 relatou estudar inglês através de materiais audiovisuais entre duas e quatro horas por dia. Tais resultados reforçam a sensibilidade às condições iniciais dos SACs (LARSENFREEMAN, 1997), uma vez que cada indivíduo se comporta de modo distinto devido à variação nas condições iniciais.

Findamos neste ponto a análise de dados do Experimento 1 com relação à variação entre os informantes da pesquisa. Na Figura 7 são apresentados dados relativos à variação individual no Experimento 2, em que buscou-se evitar a influência do grafema na realização do morfema -ed do ILA por meio da utilização de imagens. 
Figura 7: Realização alvo do morfema -ed por indivíduo no Experimento 2.

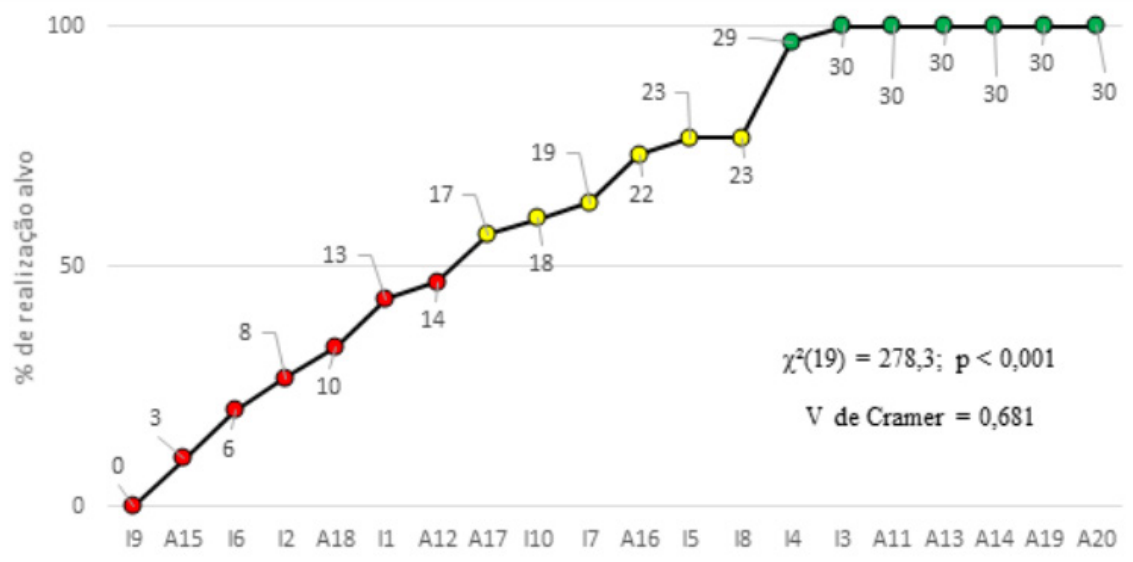

Fonte: Elaboração dos autores.

A análise estatística inferencial dos dados apresentados na Figura 7 indicou um valor alto para o qui-quadrado $\left(\chi^{2}(19)=278,3\right)$. Sendo muito baixa a probabilidade de os resultados serem decorrentes do erro amostral $(p<0,001)$. Adicionalmente, o V de Cramer obtido foi de 0,681 , indicando que cerca de $46,4 \%$ da variação na realização do morfema -ed pode ser explicada pela variável indivíduo, um percentual bastante alto. Conclui-se que a variável indivíduo influencia de modo significativo, também no Experimento 2, a emergência alvo do morfema -ed dos verbos regulares do ILA, algo esperado numa visão de língua enquanto sistema adaptativo complexo (LARSEN-FREEMAN; CAMERON, 2008). A variação entre-participantes deste estudo pode ser observada na Figura 7 e nos testes de post-hoc com a correção de Bonferroni, discutidos a seguir.

Novamente agrupamos os informantes que desfavorecem (marcadores em vermelho), apresentam comportamento neutro (amarelo) ou favorecem (verde) a forma alvo de realização do morfema -ed. Mais uma vez observamos o informante I9 como o que apresenta maior dificuldade na realização do morfema, com nenhuma das ocorrências sendo realizada de acordo com a forma alvo. Além disso, novamente observamos os informantes avançados A15 e A18 entre os que desfavorecem a forma alvo. Por sua vez, o informante A12 passa a desfavorecer a forma alvo do morfema, enquanto o informante A17 consegue sair deste atrator passando a pertencer ao grupo dos informantes neutros no Experimento 2, como discutido a seguir.

Percebemos que, de modo quantitativo, não houve diferença entre os Experimentos 1 e 2 quanto ao fato de três informantes de nível avançado desfavorecem, de modo inesperado, a emergência alvo do morfema -ed do ILA. Entretanto, percebemos Revista X, v. 16, n. 6, p. 1434-1459, 2021. 
uma alternância entre os informantes A17 e A12 que, por apresentarem-se numa região limítrofe do espaço fase, respectivamente desfavorecem e apresentam comportamento neutro quanto à realização do morfema no Experimento 1, alternando a posição no Experimento 2. A análise individual dos dados reflete o caráter ambíguo do papel do grafema na realização da forma alvo do morfema -ed. Como enfatizamos anteriormente, a literatura é contraditória quanto ao papel da escrita na realização de verbos no passado regular do inglês, ora apontando a escrita como favorecedora (ALVES, 2004), ora apontando-a como desfavorecedora (DELATORRE, 2006), da forma alvo do morfema. O acompanhamento longitudinal dos informantes tem o potencial de prover informações adicionais extremamente relevantes para o melhor entendimento do percurso de construção deste aspecto da gramática fonológica do ILA.

Mais uma vez observamos que o grupo de informantes que apresenta comportamento neutro (marcadores amarelos) é relativamente pequeno quando comparado aos grupos que desfavorecem e favorecem a forma alvo. Observa-se no gráfico que existe uma tendência por uma maior realização percentual da forma alvo pelo grupo neutro no Experimento 2 em relação ao Experimento 1. O fato é provavelmente decorrente de, nesta pesquisa, o Experimento 2 apresentar uma maior tendência pela realização da forma alvo do que o Experimento 1.

Observamos dois informantes avançados (A17,A16) entre os participantes que não desfavorecem ou favorecem a forma alvo do morfema no Experimento 2, indicando que, enquanto A17 melhorou seu desempenho, A16 piorou de modo significativo, tendo deixado o grupo de favorecedores da forma alvo do Experimento 1. Fenômenos semelhantes são observados também entre os aprendizes iniciantes, uma vez que o informante I10 destacase ao atingir o grupo neutro no Experimento 2, enquanto o informante I2 apresentou comportamento diametralmente contrário, tendo caído do grupo neutro no Experimento 1 para o grupo que desfavorece a forma alvo no Experimento 2. Conforme discutido anteriormente, a indefinição da literatura quanto à influência grafofônica na emergência da forma alvo do morfema -ed (ALVES, 2004; DELATORRE, 2006) revela-se de modo mais claro a partir da análise de dados individuais, algo que buscaremos realizar a partir destes dados iniciais por meio de um estudo longitudinal. Os dados demonstram que a falta do estímulo visual no Experimento 2 dificultou a realização do morfema -ed para o informante I2, o que reforça a dinamicidade dos SACs (LARSEN-FREEMAN, 1997), sendo este efeito sentido apenas por este informante. Quase todos os outros informantes do estudo foram claramente influenciados por um atrator distinto no Experimento 2, mais propício à forma alvo do morfema quando comparado ao Experimento 1. 
Finalmente, passamos à discussão do grupo de informantes cujas realizações favorecem a emergência da forma alvo, representados pelos marcadores verdes à direita da Figura 7. Neste grupo, chama a atenção o fato de termos dois aprendizes iniciantes, I3 e I4, entre os informantes que favorecem a forma alvo de realização do morfema -ed. Supreendentemente, o informante I3 chega a apresentar comportamento categórico (100\%) na realização da forma alvo também nos dados do Experimento 2, embora seja do grupo iniciante, o que reforça a imprevisibilidade e os comportamentos distintos dos indivíduos no sistema (LARSEN-FREEMAN, 1997). Observa-se que os informantes avançados A13, A14 e A19 também apresentam realização categórica nos Experimentos 1 e 2, enquanto os informantes A11 e A20 passam a constituir o grupo favorecedor apenas no Experimento 2.

A análise da variação entre indivíduos permite a compreensão de diferentes estágios de realização da forma alvo entre os informantes analisados. Deste modo, é possível defender a hipótese de uma variação interindividual não linear e independente de outras variáveis. A variação interindividual na realização de palavras com o morfema -ed dos verbos regulares é observada também por Gadêlha-Silva (2019).

É possível observar que cada indivíduo apresenta comportamentos distintos quanto à realização do morfema -ed. Há informantes de nível iniciante que apresentaram altos índices de realização alvo do morfema -ed (I3, I4), enquanto informantes de nível avançado apresentaram baixos índices de realização alvo (A15, A17, A18). Diante disso, reforçamos a imprevisibilidade do SAC (LARSEN-FREEMAN, 1997), bem como o princípio da sensibilidade às condições iniciais (LARSEN-FREEMAN; CAMERON, 2008), visto que cada indivíduo apresenta particularidades no percurso de aquisição da fonologia do ILA. Conclui-se, portanto, que um grande número de variáveis, entre elas a frequência, o acesso e a maneira como o aprendiz é inicialmente exposto ao ILA, para citar algumas, podem influenciar significativamente na realização do morfema -ed, conforme observado nos dados desta pesquisa. Encerramos neste momento a seção de análise e discussão dos dados, e apresentamos a seguir as considerações finais do estudo.

\section{CONSIDERAÇÕES FINAIS}

O objetivo desta pesquisa foi analisar a realização do morfema -ed dos verbos regulares por aprendizes brasileiros de inglês língua adicional. A pergunta problema que norteou este estudo foi: de que maneira as variáveis palavra e indivíduo estão associadas à realização alvo do morfema -ed dos verbos regulares do inglês? Como hipótese básica, assumimos que os aprendizes brasileiros realizam o morfema -ed de maneira complexa, Revista X, v. 16, n. 6, p. 1434-1459, 2021. 
apresentando diferenças significativas entre palavras e indivíduos, comportando-se de modo não-linear. Tendo em vista os resultados obtidos neste estudo, a hipótese básica foi confirmada, tendo em vista a análise dos dados retomada a seguir.

$\mathrm{Na}$ análise da variável palavra, foram observados itens lexicais com altos índices de realização alvo do morfema -ed (laughed, coughed saved, loved), apesar da constatação também de itens lexicais menos favoráveis à realização alvo do morfema -ed (disturbed, robbed). Os resultados obtidos nesta variável permitiram inferir que a apropriação do morfema -ed dos verbos regulares do inglês depende do item lexical. Segundo os modelos multirrepresentacionais (BYBEE, 2001; PIERREHUMBERT, 2001), as palavras comportam-se de modo distinto quanto à emergência de fenômenos de mudança linguística em língua materna, fato que parece também ocorrer na aquisição de línguas adicionais.

Por sua vez, na análise dos resultados obtidos para a variável indivíduo, alguns informantes contaram com baixo índice de realização da forma alvo, com destaque para o informante 19 , que não atingiu a forma alvo do morfema -ed em nenhuma das realizações nos dois experimentos. Alguns indivíduos apresentaram domínio da realização da forma alvo do morfema -ed do inglês (I3, A13, A14 e A19), destacando-se o informante I3 que apresentou, em ambos os experimentos, realizações alvo categóricas, mesmo tendo cerca de um ano de experiência de uso. Adicionalmente observamos que a tendência geral dos informantes desta pesquisa foi apresentar maior quantidade de realização da forma alvo no Experimento 2. Todavia, I2, A12, A16 foram influenciados por um atrator estranho que impossibilitou esta tendência geral de emergir. Estudo de cunho longitudinal são necessários para a elucidação deste tipo de comportamento complexo, algo a ser desenvolvido nos próximos anos, tendo em vista o objetivo de melhor descrição da dinamicidade observada no sistema linguístico no percurso de aquisição de uma língua adicional (LARSEN-FREEMAN, 1997).

Além da realização de um acompanhamento longitudinal dos informantes em nível iniciante desta pesquisa, em trabalhos futuros envolvendo a realização do morfema -ed, esperamos analisar quais palavras mais ou menos frequentes, ou quais contextos posteriores são mais favoráveis à realização alvo. Além disso, um estudo que considere a duração e qualidade das vogais epentéticas, averiguando as diferenças de qualidade e duração entre vogais epentéticas comparadas às vogais plenas de palavras com o morfema-ed seria também pertinente tendo em vista as lacunas apresentadas na literatura. 


\section{REFERÊNCIAS}

ALVES, U. K. O papel da Instrução Explícita na Aquisição Fonológica de Inglês como L2: Evidências Fornecidas pela Teoria da Otimidade. 2004. Dissertação (Mestrado em Letras) - Universidade Católica de Pelotas, Pelotas, 2004.

BAICCHI, A. Construction Learning as a Complex Adaptive System: psycholinguistic Evidence from L2 Learners of English. Heidelberg: Springer International Publishing, 2015.

BECKNER, C.; BLYTHE, R.; BYBEE, J.; CHRISTIANSEN, M. H.; CROFT, W.; ELLIS, N.; HOLLAND, J.; KE, J.; LARSEN-FREEMAN, D.; SCHOENEMANN, T. Language is a complex adaptive system: position paper. Language Learning, Michigan, v. 51, n. 1, p. 1-26, Dec. 2009.

BYBEE, J. Phonology and language use. Cambridge: Cambridge University Press, 2001 .

CRISTÓFARO-SILVA, T.; GOMES, C. A. Representações múltiplas e organização do componente fonológico. Fórum Linguístico, Florianópolis, v. 4, n. 1, p. 147-177, jul. 2004.

DANCEY, C. P.; REIDY, J. Estatística sem matemática para psicologia: usando SPSS para Windows. Porto Alegre: Artmed, 2006.

DELATORRE, F. Brazilians EFL Learners: Production of Vowel Epenthesis in Words Ending in -ed. 2006. Dissertação (Mestrado em Letras) - Universidade Federal de Santa Catarina, Florianópolis, 2006.

DELATORRE, Fernanda. Intelligibility of English verbs ending in -ed for brazilian learners of English as listeners. 2017. Tese (Doutorado Estudos da Linguagem) Universidade Federal de Santa Catarina, Florianópolis, 2017.

FRESE, R. A. The relationship between perception and production of words ending in -ed by Brazilian EFL learners. 2006. Dissertação (Mestrado em Letras) - Universidade Federal de Santa Catarina, Florianópolis, 2006. 
GADÊLHA-SILVA, M. Análise Fonético-Fonológica do Past Tense - ed na Produção de Aprendizes de Inglês Língua Estrangeira: uma Visão Multirrepresentacional. 2019. Trabalho de Conclusão de Curso (Licenciatura Letras - Inglês) - Universidade Federal Rural do Semi-Árido, Caraúbas, 2019.

GOMES, M. L. C. A produção de palavras do inglês com o morfema -ed por falantes brasileiros: uma visão dinâmica. Tese (Doutorado em Letras) - Universidade Federal do Paraná, Curitiba, 2009.

JOHNSON, W.; BRITAIN, D. L. Vocalisation as a natural phenomenon: explorations in sociophonology. Language Sciences, n. 29, p. 294-315, 2007.

KENT, R. D.; READ, C. Análise acústica da fala. Tradução Alexsandro Rodrigues Meireles. 1 ed. São Paulo: Cortez, 2015.

LARSEN-FREEMAN, D. Chaos/complexity science and second language acquisition. Applied Linguistics, Oxford, p. 141-165, Jun. 1997.

LARSEN-FREEMAN, D.; CAMERON, L. Complex systems and applied linguistics. Oxford: Oxford University Press, 2008.

LARSEN-FREEMAN, D. Research into Practice: Grammar Learning and Teaching. Language Teaching, v. 48, n. 2, p. 263-280, 2015.

LARSEN-FREEMAN, D. Toward a transdisciplinary integration of research purposes and methods for complex dynamic systems theory: beyond the quantitative-qualitative divide. International Review of Applied Linguistics in Language Teaching, v. ahead of print, p. 1-26, 2021. https://doi.org/10.1515/iral-2021-0022

MARIANO, M. H. The influence of training and instruction on the production of words ending in -ed by Brazilian EFL learners. 2009. Dissertação (Mestrado em Inglês e Literatura Correspondente) - Universidade Federal de Santa Catarina, Florianópolis, 2009.

MARUSSO, A. S. Princípios básicos da teoria acústica de produção da fala. Estudos da Linguagem. Belo Horizonte, v. 13, n. 1, p. 19-43, jan./jun., 2005.

PIERREHUMBERT, J. Exemplar dynamics: word frequency, lenition and contrast. In: BYBEE, J; HOPPER, P. (Comp.). Frequency effects and the emergence of linguistic structure. Amsterdam: John Benjamins, 2001. p. 137-158. 
RIELLA, R. J. Inteligibilidade de palavras terminadas com morfema ed no contexto de inglês como língua franca. 2013. Monografia (Especialização no Ensino de Línguas Estrangeiras Modernas) - Universidade Tecnológica Federal do Paraná, Curitiba, 2013.

SHARPE, D. Your Chi-Square Test is Statistically Significant: Now What?, Practical Assessment, Research, and Evaluation, v. 20, n. 8, p. 1-10, 2015.

Recebido em: 22 jul. 2021. Aceito em: 16 set. 2021. 